\title{
Head injury instructions: a time to unify
}

\author{
J Parsley, L Fletcher, A F Mabrook
}

\begin{abstract}
Objective-To compare and contrast the head injury advice given by various hospitals in England after minor head injury, and to draw attention to the need for a national set of head injury instructions. Methods-50 accident and emergency departments were contacted by post and asked to supply a copy of their head injury information card or leaflet; 41 hospitals replied $(82 \%)$.

Results-Comparison of the cards showed inconsistencies and conflicting advice given by the departments contacted.

Conclusions-There is a need for a national head injury card and a proposal for such a card is presented.

(F Accid Emerg Med 1997;14:238-239)
\end{abstract}

Keywords: head injury instructions; accident and emergency departments

It has been estimated that one million new cases of head injury attend hospital in the United Kingdom each year. ${ }^{1}$ Approximately four to five times as many patients attend as are admitted. ${ }^{2}$ The signs and symptoms associated with head injury depend on the extent of the tissue damage. ${ }^{3}$ They may appear immediately following the trauma or several hours later. It is therefore important that the relatives or friends of discharged patients should receive both verbal and written advice to alert them to any changes suggesting that the patient's injuries are more serious and that the patient should return to the hospital urgently. The purpose of this study was to examine the written advice given out by accident and emergency (A\&E) departments, to formulate a set of clear head injury instructions.

\section{Methods}

Fifty $A \& E$ departments in England were contacted by post and asked to supply a copy of their head injury card or leaflet. These were compared and the information collated to identify similarities and differences between advice given. No comparison was made between the head injury advice leaflets from hospitals with or without neurosurgical departments, or between teaching hospitals and district general hospitals. Our aim was not to highlight the differences between hospitals but to identify similarities that could be used to develop a set of instructions that would be widely acceptable.

\section{Results}

Of the 50 hospitals contacted forty one replied $(82 \%)$. Eight hospitals had neurosurgical
Table 1 Symptoms detailed on hospital head injury advice cards, with the percentage of responding hospitals listing the symptom

\begin{tabular}{lc}
\hline Headache & $90 \%$ \\
Drowsiness & $66 \%$ \\
Disturbance of vision & $46 \%$ \\
Vomiting (persistent) & $36 \%$ \\
Vomiting or nausea & $34 \%$ \\
Fits & $32 \%$ \\
Increased sleepiness & $17 \%$ \\
Unconsciousness & $15 \%$ \\
Any other unusual symptoms & $12 \%$ \\
Dizziness & $10 \%$ \\
Difficulties in awakening & $7 \%$ \\
Weakness in any of the limbs & $7 \%$ \\
Giddiness or balance problems & $7 \%$ \\
Inequality of the pupils & $5 \%$ \\
Staggering & $2 \%$ \\
Photophobia & $2 \%$ \\
\hline
\end{tabular}

Table 2 Advice given in hospital handouts, with the percentage of responding hospitals listing the advice

\begin{tabular}{lr}
\hline Avoid alcohol & $19 \%$ \\
Avoid tranquilisers & $15 \%$ \\
Do not watch television & $15 \%$ \\
Rest/observe for 24 hours & $12 \%$ \\
Take only prescribed medicine & $12 \%$ \\
Do not go home alone & $7 \%$ \\
Do not read & $7 \%$ \\
Do not play sports & $7 \%$ \\
Eat only light meals & $5 \%$ \\
\hline
\end{tabular}

facilities. Eleven hospitals sent separate cards for adults and children, and 10 stated that they were in the process of updating their cards and included other symptoms or advice that they would like to add. All cards were written in English only. Presented below are the results which for clarity have been separated into adults and children, symptoms and advice.

\section{ADULTS' SYMPTOMS}

Table 1 shows the symptoms that the hospitals participating in the survey detailed on their handouts, along with the percentage of respondents listing that symptom. However, only $41 \%$ of the respondents wrote on their card that the patient should return to the hospital if any of the symptoms occurred.

\section{ADULTS' ADVICE}

Table 2 shows the advice listed on the handouts, and the percentage of hospitals giving that advice. Not all hospitals gave advice in their handouts, but merely listed symptoms to look out for.

\section{CHILDREN'S SYMPTOMS AND ADVICE}

The results from the 11 respondents who sent a separate card relating to children are shown in table 3, which gives all the symptoms mentioned and the percentage of the respondents listing each symptom. Table 4 shows the advice provided on the cards and the percentage of respondents giving that advice. 
Table 3 Symptoms detailed on hospital head injury advice cards for children, with the percentage of responding hospitals listing the symptom

\begin{tabular}{lr}
\hline Headache & $100 \%$ \\
Persistent vomiting & $100 \%$ \\
Difficulty in awakening & $100 \%$ \\
Drowsy & $64 \%$ \\
Blurred vision & $64 \%$ \\
Fits & $55 \%$ \\
Loss of appetite & $36 \%$ \\
Increased crying & $36 \%$ \\
Sleepiness & $27 \%$ \\
Inequality of pupils & $27 \%$ \\
Confusion & $27 \%$ \\
Off colour & $18 \%$ \\
Irritable & $18 \%$ \\
Change in body temperature & $9 \%$ \\
Photophobia & $9 \%$ \\
Staggering & $9 \%$ \\
Worried parent & $9 \%$ \\
\hline
\end{tabular}

Table 4 Advice relating to children, and percentage of respondents including the advice on their cards

Check child by waking every hour but it is not necessary to keep the child awake Rest for 24 hours

Do not watch television

Take paracetamol

Do not read

Give only fluids for 24 hours

Wake child every 2 hour

\section{Discussion}

The management of more severe head injuries is well documented with the criteria for skull $x$ rays, admission for 24 hour observation, and referral to a neurosurgical centre quite clear. ${ }^{4}$ However, it is less clear what information should be given when a patient is not admitted. This study points out some of the conflicting advice given, for example "Check child every hour by waking"/"Wake child every two hours". It also shows some of the inconsistencies, for example "Do not read", given out in only $7 \%$ of cases. Conflicting advice given by hospitals and general practitioners may lead to confusion. Some advice does not appear to be backed up by published reports, for example "Do not watch television", although we suspect that this advice is given because of a concern regarding prolonged headache. Terms such as "drowsy" or "semiconscious" are open to differing interpretation.

The usefulness of head injury instruction cards has been studied elsewhere and their value questioned. The value of such cards has been enhanced by their being clearly understandable, relevant, consistent, and produced
Table 5 A suggestion for a national head injury card

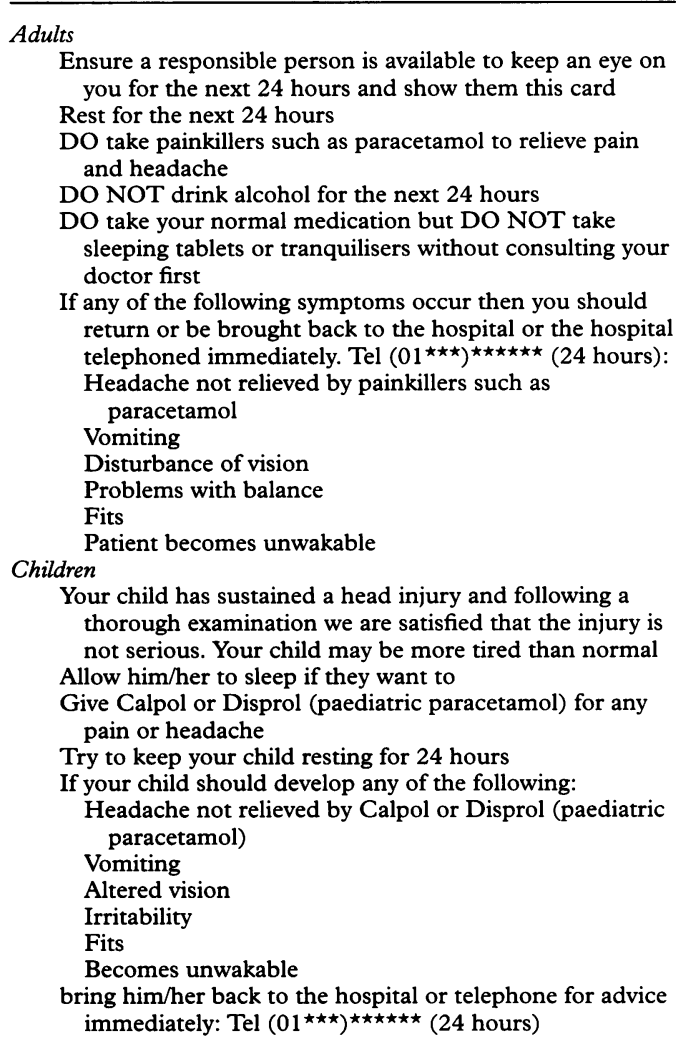

in multiple languages. There is a need for more research into head injury cards, but we believe that the introduction of a national head injury instruction card would enhance the card's value for patients and aid research. Our suggestion is given in table 5 . The card has been given to a series of $A \& E$ department attenders in our hospital: 40 were given the adults' advice card and 20 the children's advice card. We determined that 12 were unaware that a patient who had sustained a head injury could be given analgesia, and nine did not realise that it was acceptable to allow a child to sleep following a head injury. None of the 40 had problems in understanding the card.

1 Jennett B, Murray R, MacMillan R, MacFarlane J, Bentley C, Strang I, et al. Head injuries in Scottish hospitals. Lancet $1977 ; \mathrm{ii}: 696-8$.

2 Strang I, MacMillan R, Jennett B. Head injuries in accident and emergency departments at Scottish hospitals. Injury

3 Goldstein J. Posttraumatic headache and the postconcussion syndrome. Med Clin North Am 1991;75:641-51.

4 Gion syndrome. Med Clin North Am 1991;75:641-51. ment after head injury in adults. BMJ 1984;288:983-5. 